\title{
Editorial
}

\section{COVID-19 Pandemic: Effect on Medical Education}

\author{
Islam $\mathrm{MT}^{1}$, Pasha $\mathrm{AKMMK}^{2}$
}

DOI: https://doi.org/10.3329/jafmc.v16i1.53845

The corona virus disease 2019 (COVID-19) caused by novel Corona virus (SARS-COV-2) has become the fifth documented pandemic in the world. Previous pandemic were Spanish flu in 1918, Asian flu in 1957, Hong Kong flu in 1968 and swine flu in 2009. COVID-19 was first reported in Wuhan, China and subsequently spread worldwide. The earliest date of detection of symptom was on 1st December 2019. The symptomatology of these patients, including fever, malaise, dry cough, and dyspnea, was diagnosed as viral pneumonia. Initially, the disease was called Wuhan pneumonia by the press because of the area and pneumonia like symptoms. The World Health Organization (WHO) temporarily termed the new virus 2019 novel corona virus (2019-nCoV) on 12 January 2020 and then officially named this infectious disease corona virus disease 2019 (COVID-19) on 12 February 2020. Later, the International Committee on Taxonomy of Viruses (ICTV) officially designated the virus as Severe Acute Respiratory Syndrome Coronavirus-2 (SARS-CoV-2). Since its emergence in China, the virus has evolved for four months and rapidly spread to other countries worldwide as a global threat. On 11 March 2020, the WHO declared as a pandemic ${ }^{1}$.

All human coronaviruses have animal origins, namely, natural hosts. Bats were considered as the natural hosts of SARS CoV. Domestic animals can suffer from this disease as intermediate hosts that cause virus transmission from natural hosts to humans. Bats are likely reservoir hosts for SARS-CoV-2; however, direct transmission to humans or transmits to intermediate hosts to facilitate animal-tohuman transmission remains inconclusive ${ }^{1}$.

Evolving epidemiologic evidence determined COVID-19's capacity to spread through human-to-human droplet transmissions. A subsequent study identified the presence of the virus in stool samples of an infected host, suggesting the potential for fecal-oral spread ${ }^{2}$. Recently The Lancet published a paper named "Ten scientific reasons in support of airborne transmission of SARS-CoV-2". There is consistent, strong evidence that SARS-CoV-2 spreads by airborne transmission. Although other routes can contribute, the airborne route is likely to be dominant ${ }^{3}$.
The COVID-19 has affected the global education system and temporarily pushing the majority of students out of school. In an attempt to control the devastating spread of COVID-19, there was nationwide shutdown across 150 countries affecting almost $80 \%$ of the world student population, according to UNESCO. Economic recession impacted heavily on students all over the world as well. According to UNICEF, in South Asia, almost 430 million children are affected by school shut down and are at risk of dropping out of the education system due to the economic impact on their families. On March 16, 2020 the Government of Bangladesh declared closures to all academic institutions, dormitories and coaching centers as well, with the growing public concern the closure period got extended time to time ${ }^{4}$.

This longtime closure due to COVID-19 pandemic is negatively impacting the overall learning capacity of the students, as well as significantly affecting the mental health and growth of these young minds. On April 30, 2020, the government asked the public and private universities to continue their curriculum through online classes and start their academic activities online. There are immense benefits of online education services but availability of uninterrupted and adequate internet access is challenging for universal use ${ }^{4}$.

Biotechnology Enhancement and Development (BioTED) has recently published an article in an English newspaper. They surveyed on 2038 students from forty two different public and private universities from May 9 to May 11, 2020. BioTED has found only $23 \%$ of the total students are attending the online class and the reasons for that are multiple like lack of internet access, device and supervision ${ }^{5}$.

According to the University Grants Commission of Bangladesh (UGC) \& Bangladesh Medical and Dental Council (BMDC), there are 155 public and private Universities in Bangladesh and 117 medical and dental colleges under these universities. More than one million students are studying at these Institutions. During the situation of the pandemic, all the Universities and Medical and Dental colleges are remaining closed since April $2020^{6}$.

1. Brig Gen Md Tanvirul Islam, MBBS, FCPS, Professor \& Head, Department of Surgery, AFMC, Dhaka (E-mail: tanvirmail@gmail.com) 2. Maj Gen AKM Mustafa Kamal Pasha, SPP, ndc, MPhil, MPH, Commandant, AFMC, Dhaka. 
The widespread termination of clinical placements, face to face teaching and examinations that require a physical presence made an unprecedented disruption on the delivery of medical education. The lack of regular communication between students and tutors impede academic performance and give rise to burnout within students.

Armed Forces Medical College and five Army Medical Colleges discussed the issue and started to take online classes with the help of ZOOM from the early days of pandemic, in all pre-clinical and clinical subjects. Online lectures have been well accepted by all students of AFMC. Due to suspended clinical placements, students' clinical skills, competence may decline as they have no opportunity to bed side teaching. Both written and practical assessments have also been considerably hampered by the pandemic across all medical colleges.

AFMC has successfully completed the first, second and third professional MBBS examinations in between January 2021 to April 2021 with strict compliance to National guidelines and there was no incidence of covid-19 infection among the students. The clinical and viva examination of regular final professional MBBS is suspended due to the sudden rise of covid-19 infection rate in March-April 2021 countywide. The Bangladesh University of Professionals, Armed Forces Medical College and the Army Medical Colleges have made a plan to take the examinations within a short term notice after withdrawal of nationwide lockdown. AFMC students are fully motivated and mentally prepared to sit for the examination.
Our earlier experience regarding the internship training in this pandemic is frustrating. Due to panic and fears, many interns of different hospitals have omitted themselves from the duties or did not join to their internship program. We should have a comprehensive internship training program considering the complex situation of covid-19 pandemic to make a competent and confident medical graduate.

\section{References}

1. Liu YC, Kuo RL, Shih SR. COVID-19: The first documented coronavirus pandemic in history. Biomedical Journal 2020; 43:328-33.

2. Baghchechi M, Jaipaul N, Jacob SE. The rise and evolution of COVID-19. International Journal of Women's Dermatology 2020; 6:248-54.

3. Greenhalgh T, Jimenez JL, Parther KA et al. Ten scientific reasons in support of airborne transmission of SARS-CoV-2. The Lancet 2021; 397(10285):1603-5.

4. Barua A. The impact of COVID-19 Pandemic: Education sector of Bangladesh; 2020. Available at https://bipss.org.bd/the-impact-of-covid-19 -pandemic-education-sector-of-bangladesh/

5. Islam DMS, Tanvir K, Amin DM et al. Online classes for university students in Bangladesh during the Covid-19 pandemic- is it feasible?; 2020. Available at https://tbsnews.net/thoughts/online-classes-universitystudentsbangladesh-during-covid-19-pandemic-itfeasible-87454.

6. Emon EKH, Alif AR, Islam MS. Impact of COVID-19 on the Institutional Education System and its Associated Students in Bangladesh. Asian Journal of Education and Social Studies 2020; 11(2):34-46. 